\title{
Thermal Index for Early Non-invasive Assessment of Brain Injury in Newborns Treated With Therapeutic Hypothermia - Preliminary Report of Non-invasive Thermal Measurements
}

\section{Wojciech Walas}

Paediatric and Neonatal Intensive Care Unit, Institute of Medical Sciences, University of Opole, Opole Anna Mączko

Paediatric and Neonatal Intensive Care Unit, Institute of Medical Sciences, University of Opole, Opole

\section{Zenon Halaba}

Department of Paediatrics, Institute of Medical Sciences, University of Opole, Opole

\section{Monika Bekiesińska-Figatowska}

Department of Diagnostic Imaging, Institute of Mother and Child, Warsaw

\section{Iza Miechowicz}

Department of Computer Science and Statistics, Poznan University of Medical Sciences, Poznan

\section{Dominka Bandoła}

Biomedical Engineering Laboratory, Department of Thermal Technology, Silesian University of

Technology, Gliwice

\section{Ziemowit Ostrowski}

Biomedical Engineering Laboratory, Department of Thermal Technology, Silesian University of

Technology, Gliwice

\section{Marek Rojczyk}

Biomedical Engineering Laboratory, Department of Thermal Technology, Silesian University of

Technology, Gliwice

Andrzej Nowak ( $\sim$ andrzej.j.nowak@polsl.pl )

Biomedical Engineering Laboratory, Department of Thermal Technology, Silesian University of Technology, Gliwice

\section{Research Article}

Keywords: Newborn, perinatal asphyxia, therapeutic hypothermia, brain injury, magnetic resonance imaging, thermal index

Posted Date: January 20th, 2021 
DOl: https://doi.org/10.21203/rs.3.rs-145824/v1

License: (c) (1) This work is licensed under a Creative Commons Attribution 4.0 International License. Read Full License 


\section{Abstract}

Perinatal asphyxia (PA) is the 3rd most common cause of neonatal death and one of the most common causes of severe neurological impairments in children. Current tools and measurements mainly based on the analysis of clinical evaluation and laboratory and electrophysiological tests do not give consistent data allowing to predict the severity of hypoxic-ischemic encephalopathy (HIE) until an magnetic resonance imaging (MRI) score is performed. The aim of this work is to evaluate the usefulness of the new index, called Thermal Index (TI) in the assessment of the degree of brain damage in newborns in the course of therapeutic hypothermia $(\mathrm{TH})$ due to PA.

This was a prospective, observational, pilot study which did not require any changes in the applicable procedures. Analysis has been applied to six newborn babies treated with TH in Neonatal/Paediatric ICU in University Hospital in Opole in 2018 due to PA. They all met criteria for TH according to the current recommendations. Brain MRI was performed after the end of TH when the children were brought back to normal temperature, with the use of 1.5 T scanner, using T1-, T2-weighted images, fluid-attenuated inversion recovery (FLAIR), inversion recovery (IR), susceptibility-weighted imaging (SWI), and diffusionweighted imaging (DWI). The images were assessed using MRI score according to the scoring system proposed by Weeke et al. The Thermal Index assessing endogenous heat production was calculated according to the formula proposed in this paper. High, statistically significant positive correlation were found between MRI scores and TI values $(0.98 ; p=0.0003)$ in the 1 st hour of therapy.

High correlation with MRI assessment, the non-invasiveness of measurements and the availability of results within the first few hours of treatment, allow authors to propose the Thermal Index as a tool for early evaluating of the brain injury in newborns treated with $\mathrm{TH}$. Further research is required to confirm the usefulness of the proposed method.

\section{Introduction}

Perinatal asphyxia (PA) represents the 3rd most common cause of neonatal death. This means that all over the world, almost 600,000 newborns die every year, and at least as many develop hypoxic-ischemic encephalopathy (HIE), which is one of the most common causes of severe neurological deficits in children, presently in approx. 15 out of 10,000 live births ${ }^{1,2}$. Among the various methods tested for efficacy in newborns with PA, therapeutic hypothermia $(\mathrm{TH})$ has proved to be useful in clinical practice ${ }^{3,4}$. Early evaluation of the degree of brain damage in newborns after PA is of great importance in determining the appropriate management and prognosis. In the initial phase of treatment this assessment is based on a complex analysis of different factors, such as clinical evaluation of neurological status, laboratory, and electrophysiological tests. Although hypoxia markers and electrophysiological tests have been studied many times and are quite widely used in clinical practice, there are currently no consistent data to establish thresholds corresponding to HIE severity and the predictive value of individual tests for subsequent outcomes leaves a great deal to be desired ${ }^{5,6}$. Neuroimaging, especially magnetic resonance imaging (MRI), plays a special role in determining the 
prognosis of newborns after PA. Both conventional and newer MRI techniques are used and MRI is nowadays a standard tool for determining the pattern and severity of brain injury as well as the prognosis in infants with $\mathrm{HIE}^{7-12}$. Scales for objective, numerical assessment of the degree of brain damage in neonates with HIE were developed ${ }^{13-17}$. However, while MRI is very useful for predicting the consequences of PA, it cannot be performed in an Intensive Care Unit (ICU), so it is not suitable for assessing neonatal brain damage during $\mathrm{TH}$ treatment. Therefore early assessing the degree of brain damage and prognosis in newborns with HIE treated with TH remains a challenge and new methods are being sought for.

Because PA causes a dysfunction of the thermoregulation center, the methods of assessing the degree of brain injury and prognosis based on a non-invasive estimation of endogenous heat production have also garnered interest recently, and preliminary results are encouraging. The relationship between disturbances in thermoregulation and prognosis in patients with traumatic brain injury and after cardiac arrest has been proven ${ }^{18-27}$. Even some simple methods of assessing brain damage in adult patients after cardiac arrest and in newborns after PA have been proposed ${ }^{28-30}$. However, these methods result in a Heat Index $(\mathrm{HI})^{28}$ and utilize temperature of the cooling water only. Hence, from the heat transfer point of view, its theoretical basis is limited, because temperature of the cooling water is not the only factor that defines the heat rate during $\mathrm{TH}$.

A new methodology of analyzing the cooling process (allowing to estimate thermogenesis) of newborns with HIE undergoing TH has been presented in ${ }^{31,32}$. The proposed method, with roots in heat transfer theory, takes into account more factors influencing the heat transfer and employs only the non-invasive thermal measurements. Following this methodology, a Thermal Index (TI) is now proposed in order to early assess the degree of brain damage in newborns after PA treated with $\mathrm{TH}$. The aim of the presented pilot study is to evaluate the usefulness of this method in clinical practice. In newborns with PA treated with $\mathrm{TH}$, we compared the levels of $\mathrm{TI}$ as well as the levels of Apgar score and selected biochemical parameters with the brain MRI scores performed after the end of TH treatment.

\section{Type of study}

This was a prospective, observational pilot study which did not require any changes from the standard treatment of included patients.

\section{Materials And Methods}

- Patients

Six neonates with PA, treated using TH in Paediatric ICU in Opole, Poland in 2018 were included in the study after obtaining the consent of their legal guardians. Inclusion criteria for the $\mathrm{TH}$ treatment were in accordance with current recommendations:

1) gestational age at birth $\geq 35$ weeks, and 
2) birth weight $\geq 1800 \mathrm{~g}$, and

3) Apgar score $\leq 5$ in $1 \mathrm{st}, 3 \mathrm{rd}$, 5th, and 10th minute after birth and / or the need of artificial ventilation for the neurological reasons in the 10th minute after birth, and

4) deep acidosis: $\mathrm{pH}$ in the cord or arterial blood $\leq 7,0$ and/or Base Excess (BE) $\leq 16 \mathrm{mmol} / \mathrm{l}$ in the cord, arterial or venous blood in the 1 st hour after birth, and

5) neurological disorders: variable states of consciousness and at least one of the symptoms: muscle hypotension, abnormal reaction to stimuli (including abnormal oculomotor and/or pupillary reflex), no or weak sucking reflex, seizures.

Exclusion criteria were as follows:

1) $>6$ hours after birth, and/or

2) gestational age $<35$ weeks, and/or

3) birth weight $<1800$ g., and/or

4) severe birth defects with poor prognosis, and/or

5) severe coagulopathy, and/or

6) massive intracranial hemorrhage, and/or

7) extremely severe hypoxia with Apgar score $=0$ at 10 th minute after birth.

Amplitude integrated electroencephalography (aiEEG) was used as an additional criterion for qualifying for $\mathrm{TH}$ treatment in doubtful situations.

- Therapeutic hypothermia treatment

Newborns after PA admitted to Paediatric ICU were qualified for TH treatment based on clinical/biochemical criteria. Cranial ultrasound, laboratory tests and aiEEG were performed within 30 minutes of admission. After confirming the indications and ruling out contraindications, TH was started with the Olympic Cool-Cap (Olympic Medical, division of Natus, USA) device. The treatment was carried out for 72 hours under rectal temperature control, which was maintained in the range of $34-350 \mathrm{C}$. The treatment was conducted in accordance with the rules adopted in the ward and the study did not affect its course.

- Collecting data

- Clinical data: Based on the documentation from the delivery room, the type of delivery (natural/cesarean section), gender (male/female), gestational age (weeks), birth weight (grams), and Apgar scores in the 1., 5., and 10. minutes after birth were recorded. 
- Laboratory tests: Within 30 minutes of admission to the department, selected biochemical parameters were evaluated: $\mathrm{pH}$ (arterial blood), Aspartate Aminotranspherase (AspAt), Alanine Aminotranspherase (AIAt), Creatine Kinase [Muscle, Brain] (CKMB), High-Sensitivity Troponin T (HSTNT).

- MRI assessment: The MRI was performed after the end of TH and after the newborn had reached a normal temperature. Brain MRI was performed with use of a 1,5 T scanner, using T1-, T2-weighted images, fluid-attenuated inversion recovery (FLAIR), inversion recovery (IR), susceptibility-weighted imaging (SWI) and diffusion-weighted imaging (DWI) sequences. The images were assessed using MRI score (MRIS) according to the scoring system proposed by Weeke et al. ${ }^{16}$. The higher score, the more serious brain injury. The lowest possible score was 0 , and the highest was 55 .

- Thermal Index (TI): As described by Walas et al. ${ }^{32}$ the heat balance for the neonate undergoing $\mathrm{TH}$ reads

$$
Q_{m}=\frac{\mathrm{d} U}{\mathrm{~d} \tau}+Q_{\text {grin }}+Q_{\text {resp }}
$$

where $Q_{m}$ represents the rate of metabolic heat production, $Q_{s k i n}$ is the rate of heat dissipated through the skin (to the local indoor environment) while $Q_{\text {resp }}$ stands for the rate of heat exchanged due to respiration. These three heat rates are all expressed in watts $(W)$. The time derivative on the right-hand side of the equation accounts for changes of neonate's body internal energy $U$ with respect to time. In the proposed study, internal energy $U$ has been determined as a function of tissues temperatures (based on two terms related to skin and core compartment temperature measurements).

Summation of $Q_{s k i n}$ and $Q_{\text {resp }}$ represents the total heat rate exchanged by the neonate with cooling water and a local indoor environment. In case of the selective hypothermia, the dominant term of $Q_{s k i n}$ heat rate is the heat exchanged between neonate's head and cooling water flowing through a cooling cap. Amount of heat $Q_{\text {cooling }}$ that is determined as the energy exchanged in this way in the early phase of TH (for instance during the first hour) can be treated as a driving quantity of $\mathrm{TH}$ process.

On the other hand, the decrease of neonate's core temperature, or more precisely decrease of internal energy $\Delta U$ during the same time period can be seen as a direct effect of the cooling process. The ratio of these two quantities, i.e. $\Delta U$ and $Q_{\text {cooling, }}$ represents the effectiveness of the cooling process, which depends on the degree of brain damage. Finally, the above described ratio TI is related to neonate's body weight $W$ and scaled to make results comparable with the MRIS ${ }^{16}$ results:

$$
\pi=\frac{1}{W} \frac{\Delta U}{Q_{\text {coding }}}
$$

Details how quantities of $\Delta U$ and $Q_{\text {cooling }}$ should be calculated based on non-invasive measurements during $\mathrm{TH}$ are given in the study by Walas et al. ${ }^{32}$. 
- Statistical analysis:

Since the MRIS is measured on an ordinal scale, nonparametric tests were used. In order to investigate the relationship between the MRIS and other analyzed parameters, the Spearman rank correlation coefficient was calculated. Kendall's W coefficient of concordance with chi-square test was calculated to determine the agreement between the MRIS and the TI. First, however, the min-max normalization was used for MRIS, $\mathrm{TI}$ and $\mathrm{pH}$ to change their values to the range $[0 ; 1]$. Statistica 12 by StatSoft and PQStat by PQStat Software were used.

- Ethics statement

The research is not a clinical trial and therefore does not need to be registered. The study protocol was consistent with the ethical guidelines of the Declaration of Helsinki and its later amendments and current EU guidelines and regulations. The study was approved by the Bioethics Committee for Research Studies at the Opole Medical Chamber (Approval No 271/2018 and 272/2018). Written informal consent was obtained from all legal guardians of all study participants.

\section{Results}

We included 6 newborns in the study. The characteristics of the group as well as the results are presented in Table 1. All newborns had abnormal aiEEG recordings, but there was no need to include this test in the TH decision because they met the clinical/biochemical qualification criteria for this treatment. Statistical analysis is presented in Table 2. and in Fig. 1. 
Table 1

Characteristics of the studied group and levels of analyzed parameters in patients 1-6.

\begin{tabular}{|c|c|c|c|c|c|c|}
\hline \multirow[t]{2}{*}{ Parameter } & \multicolumn{6}{|l|}{ Patient } \\
\hline & 1 & 2 & 3 & 4 & 5 & 6 \\
\hline & \multicolumn{6}{|c|}{ Characteristics of the studied group } \\
\hline $\begin{array}{l}\text { Gender } \\
(\mathrm{m} / \mathrm{f})\end{array}$ & $\mathrm{m}$ & $\mathrm{m}$ & $\mathrm{m}$ & $f$ & $f$ & $\mathrm{~m}$ \\
\hline $\begin{array}{l}\text { Type of delivery } \\
\text { (n / cs) }\end{array}$ & $\mathrm{n}$ & cs & $\mathrm{n}$ & cs & $\mathrm{n}$ & cs \\
\hline $\begin{array}{l}\text { Gestational age } \\
\text { (weeks + days }\end{array}$ & $41+0$ & $40+1$ & $39+0$ & $40+2$ & $40+0$ & $39+4$ \\
\hline \multirow[t]{2}{*}{$\begin{array}{l}\text { Birth weight } \\
\text { (g) }\end{array}$} & 3290 & 2140 & 3200 & 3130 & 3260 & 3680 \\
\hline & \multicolumn{6}{|c|}{ Levels of analyzed parameters } \\
\hline Apgar 1. min. & 4 & 1 & 3 & 1 & 1 & 1 \\
\hline Apgar 5. min. & $7^{*}$ & 3 & 5 & 4 & 5 & $8^{*}$ \\
\hline Apgar 10. min. & $7 *$ & 4 & $6^{*}$ & $6^{*}$ & $6^{*}$ & $8^{*}$ \\
\hline $\mathrm{pH}$ & 6.92 & 6.83 & 7.00 & 7.14 & 6.90 & 7.04 \\
\hline $\begin{array}{l}\text { AspAt } \\
(\mathrm{U} / \mathrm{I})\end{array}$ & 98 & 21 & 49 & 43 & 95 & 47 \\
\hline $\begin{array}{l}\text { AlAt } \\
(\mathrm{U} / \mathrm{I})\end{array}$ & 21 & 5 & 22 & 20 & 28 & 23 \\
\hline $\begin{array}{l}\text { CK-MB } \\
(\mathrm{ng} / \mathrm{ml})\end{array}$ & 63.89 & 81.75 & 37.40 & 49.15 & 140.40 & 20.60 \\
\hline $\begin{array}{l}\text { HSTNT } \\
(\mathrm{ng} / \mathrm{l})\end{array}$ & 617.60 & 76.43 & 91.36 & 83.13 & 151.10 & 141.90 \\
\hline TI & 0.01891 & 0.00750 & 0.02212 & 0.03348 & 0.02556 & 0.03265 \\
\hline MRIS & 1 & 0 & 1 & 5 & 3 & 4 \\
\hline
\end{tabular}

m- male, f- female, $n$ - natural, cs- cesarean section

* artificial ventilation for neurological reasons needed in the 10th minute after birth 
Table 2

Correlation between the MRI scale (MRIS) and the analyzed parameters (the Spearman rank correlation coefficient)

\begin{tabular}{|llll|}
\hline MRIS \& & parameter & Rs coefficient & p-value \\
& TI & 0.9856 & $0.0003^{*}$ \\
Apgar 1. min. & -0.4116 & 0.4175 \\
Apgar 5. min. & 0.2794 & 0.5918 \\
Apgar 10. min. & 0.4620 & 0.3563 \\
pH & 0.8117 & $0.0499 *$ \\
AspAt & -0.0290 & 0.9565 \\
AlAt & 0.3479 & 0.4993 \\
Ck-MB & -0.3769 & 0.4615 \\
HSTNT & 0.1160 & 0.8268 \\
\hline
\end{tabular}

* - significant correlation $(p<0.05)$

\section{Discussion}

MRI is nowadays a standard tool for determining the pattern and severity of brain injury as well as the prognosis in infants with HIE. The usefulness of conventional and modern MRI techniques, such as: T2*weighted imaging (GRE/T2*WI), susceptibility-weighted imaging (SWI), diffusion-weighted imaging (DWI), as well as the magnetic resonance spectroscopy (MRS), diffusion tensor imaging (DTI) has been proven $^{7-12}$. Scoring scales have also been developed to quantify hypoxic brain injury ${ }^{13-16}$. Since MRI is considered to be the best predictor of brain damage, we looked for a correlation between it and Apgar score and biochemical test results. We used the scale proposed by Weeke et al. ${ }^{17}$. In our opinion, this scale is the most suitable for assessing brain damage in the first days of life because it covers the largest range of possible pathological changes and the broadest range of MRI techniques thus allowing for the most detailed assessment. Moreover, it offers a simpler and more unequivocal scoring method than other scales. The predictive value of the scoring system by Weeke et al. for outcome at 2 years of age and at school age has been proven ${ }^{17}$.

In our study, we found a significant positive correlation between the MRIS and $\mathrm{TI}(p=0.0003)$ and between MRIS and $\mathrm{pH}(\mathrm{p}=0.0499)$. The strength of correlation was greater between the MRIS and the TI than between MRIS and $\mathrm{pH}(\mathrm{Rs}=0.9856$ vs Rs $=0.8117)$. The concordance between the MRIS and the TI was very high (Kendall's W $=0.9928$, the average Spearman rank correlation coefficient $=0.9855$ ), although unfortunately, due to the very small sample size, it was not statistically significant $(p=0.0773)$. There was no significant correlation between the MRIS and other considered parameters. 
Our results are in line with those obtained by adult patients after cardiac arrest (CA). Murnin et al. proposed the use of estimated endogenous heat production to establish prognosis in patients after CA treated by $\mathrm{TH}$. They estimated the endogenous heat production using so-called Heat Index $(\mathrm{HI})$, which was calculated based only on the temperature of water pumped by the cooling device. They found that in cardiac arrest patients receiving $\mathrm{TH}$, greater heat generation is associated with better baseline health, reduced ischemic injury, and improved neurologic function, which results in higher metabolism ${ }^{28}$. These observations were confirmed by Uber et al., who also used $\mathrm{HI}$. They demonstrated that increased energy required by a cooling device to cool a patient after CA to target temperature is associated with improved outcomes at hospital discharge ${ }^{29}$. Similar observations were made for neonates after PA treated by TH. Mietzsch et al. noted that the temperature of the active cooling medium correlates with the severity of brain injury diagnosed by MRI. A significantly higher cooling device output temperature was seen in infants with an unfavorable outcome. Infants with significant grey matter injury on MRI require less active cooling to maintain target temperature during TH. The authors concluded that the cooling device output temperature has the potential to be an easily accessible physiological biomarker and a predictor of injury and mortality in neonates with moderate or severe $\mathrm{HIE}^{30}$.

In our study, we used the methodology of the heat balance proposed by Bandoła et al. ${ }^{31}$, further developed by Walas et al. ${ }^{32}$. These authors presented examples of the measurements of the proposed parameters during TH in newborns, but they did not present the results of studies confirming the clinical usefulness of the proposed method. This methodology is based on a larger number of non-invasive measurements performed during TH treatment than used by Murnin et al., Uber et al. and Mietzsch et al. ${ }^{28-30}$. Therefore, it seems that it may be more accurate and less susceptible to external factors while maintaining the value of full non-invasiveness.

We found also a significant correlation between MRIS and $\mathrm{pH}$, although the strength of this correlation was weaker than between MRIS and TI. This is consistent with other reports. Among the laboratory tests, the acid-base balance holds a special place, because metabolic acidosis is the second prequalification criterion for TH treatment. Shah et al., Ambalavanan et al. and Wayock et al. have demonstrated the importance of metabolic acidosis in predicting neonatal outcomes ${ }^{33-35}$. According to a systematic literature review and meta-analysis by Malin et al., strong, consistent, and temporal association between low umbilical arterial $\mathrm{pH}$ and clinically important neonatal outcomes has been proven ${ }^{36}$.

In our study, we found no correlation between MRIS and the Apgar score in 1st, 5th and 10th minute after birth. This observation is in line with the literature. The Apgar scale is commonly used to assess the condition of the newborn at birth, it is also one of the basic criteria for pre-qualification for TH treatment. However, the value of this parameter as a predictor of PA consequence is doubtful. Laptook et al. showed that the Apgar score at 10th min. provides useful prognostic data for infants with HIE, because death or moderate/severe disability is common, but not uniform when the Apgar score is $<3$, while Shah et al. found that $1 / 3$ of infants with Apgar score $=0$ at 10 th min. who survived to reach the ICU, had normal scores of formal development assessments ${ }^{37,38}$. We also found no correlation between MRIS and AspAt, 
AIAt, CKMB, HSTNT levels. Liver enzymes and myocardial injury biomarkers are often measured in neonates after PA, but their prognostic significance is ambiguous. Although Muniraman et al. demonstrated a relationship between the degree of hypoxia and aminotranspherases levels, and Agrawal et al. showed that elevated CKMB levels are found in newborns with a worse prognosis, however, these observations were not broadly confirmed ${ }^{39,40}$. Türker et al. showed that significant elevation of cord cardiac troponin I (cTnl) is an early predictor of mortality in term infants after PA and Montaldo et al. as well as Shastri et al. noted that the concentrations of this enzyme after birth correlate with the clinical grade of $\mathrm{HIE}^{41-43}$. However, the studies performed by Trevisanuto et al. and by Zhou et al. show that the relationship between prognosis and cTnl levels in newborns after PA may be mainly due to myocardial damage ${ }^{44,45}$.

Our pilot study was performed on a very small group of patients and the conclusions must therefore be treated with some reserve. However, we decided to publish our results because this is the first study to initially confirm the usefulness of a new non-invasive method for an early prognosis of HIE severity.

\section{Conclusion}

Preliminary results allow us to propose the Thermal Index as new non-invasive tool for early evaluation degree of brain injury in newborns undergoing $\mathrm{TH}$, that shows significant correlation with the MRI assessment. It is necessary to confirm the obtained preliminary results on a larger group of patients.

\section{Declarations}

\section{Funding}

The study is supported by the National Science Centre (NCN), Poland, within the project no UMO2018/29/B/ST8/01490.

\section{Author contributions}

WW, MBF, IM, and AJN conceived and designed the research. MBF, IM, MR, AM and DB conducted the measurements and other experiments. WW, MBF, IM, ZO, ZH, and AJN analyzed the data. WW, IM, ZO, and AJN wrote the manuscript.

\section{Code availability}

All calculations related to statistical analysis have been made in Statistica 12 by StatSoft and PQStat by PQStat Software. Thermal calculations and presentation of results have been prepared using Matlab

\section{Consent for publication}

Not applicable 


\section{References}

1. Graham EM, Ruis KA, Hartman AL, Northington FJ, Fox HE. A systematic review of the role of intrapartum hypoxia-ischemia in the causation of neonatal encephalopathy. Am J Obstet Gynecol. 2008;199(6): 587-595.

2. World Health Organization. http://www.childmortality.org/. Global Health Observatory (GHO); WHO 2016. Accessed April 10, 2020.

3. Jacobs SE, Berg M, Hunt R, Tarnow-Mordi WO, Inder TE, Davis PG. Cooling for newborns with hypoxic-ischaemic encephalopathy. Cochrane Syst Rev. 2013;2013(1):CD003311.

4. Wyllie J, Bruinenberg J, Roehr CC, Rüdiger M, Trevisanuto D, Urlesberger B. European Resuscitation Council Guidelines for Resuscitation 2015. Section 7. Resuscitation and support of transition of babies at birth. Resuscitation. 2015;95:249-263.

5. Liu W, Yang Q, Wei H, Dong W, Fan Y, Hua Z. Prognostic Value of Clinical Tests in Neonates With Hypoxic-Ischemic Encephalopathy Treated With Therapeutic Hypothermia: A Systematic Review and Meta-Analysis. Front Neurol. 2020 Feb 25;11:133.

6. Walas W, Wilińska M, Bekiesińska-Figatowska M, Halaba Z, Śmigiel R. Methods for assessing the severity of perinatal asphyxia and early prognostic tools in neonates with hypoxic-ischemic encephalopathy treated with therapeutic hypothermia. Adv Clin Exp Med. 2020 Aug;29(8):1011-1016.

7. Thayyil S, Chandrasekaran M, Taylor A, Bainbridge A, Cady EB, Chong WK, Murad S, Omar RZ, Robertson NJ. Cerebral magnetic resonance biomarkers in neonatal encephalopathy: a metaanalysis. Pediatrics. 2010 Feb;125(2):e382-95.

8. Cheong JL, Coleman L, Hunt RW, Lee KJ, Doyle LW, Inder TE. Prognostic utility of magnetic resonance imaging in neonatal hypoxic-ischemic encephalopathy: substudy of a randomized trial. Arch Pediatr Adolesc Med. 2015;166:634-640.

9. Bekiesinska-Figatowska M, Duczkowska A, Szkudlinska-Pawlak S, Duczkowski M, Madzik J, Cabaj A, Krupa K, Peczkowski P, Bragoszewska H. Diffusion restriction in the corticospinal tracts and the corpus callosum in neonates after cerebral insult. Brain Dev. 2017 Mar;39(3):203-21.

10. Rana L, Sood D, Chauhan R, Shukla R, Gurnal P, Nautiyal H, Tomar M. MR Imaging of hypoxic ischemic encephalopathy - Distribution Patterns and ADC value correlations. Eur J Radiol Open. 2018 Nov 16;5:215-220.

11. Mitra S, Kendall GS, Bainbridge A, Sokolska M, Dinan M, Uria-Avellanal C, Price D, Mckinnon K, Gunny R, Huertas-Ceballos A, Golay X, Robertson NJ. Proton magnetic resonance spectroscopy lactate/Nacetylaspartate within 2 weeks of birth accurately predicts 2-year motor, cognitive and language outcomes in neonatal encephalopathy after therapeutic hypothermia. Arch Dis Child Fetal Neonatal Ed. 2019 Jul;104(4):F424-F432.

12. Lemmon ME, Wagner MW, Bosemani T, Carson KA, Northington FJ, Huisman TAGM, Poretti A. Diffusion Tensor Imaging Detects Occult Cerebellar Injury in Severe Neonatal Hypoxic-Ischemic Encephalopathy. Dev Neurosci. 2017;39(1-4):207-214. 
13. Trivedi SB, Vesoulis ZA, Rao R, Liao SM, Shimony JS, McKinstry RC, Mathur AM. A validated clinical MRI injury scoring system in neonatal hypoxic-ischemic encephalopathy. Pediatr Radiol. 2017 Oct;47(11):1491-1499.

14. Rutherford M, Ramenghi LA, Edwards AD, Brocklehurst $P$, Halliday $H$, Levene $M$. Assessment of brain tissue injury after moderate hypothermia in neonates with hypoxic-ischaemic encephalopathy: a nested substudy of a randomised controlled trial. Lancet Neurol. 2010;9:39-45.

15. Shankaran S, Barnes PD, Hintz SR, Laptook AR, Zaterka-Baxter KM, McDonald SA. Brain injury following trial of hypothermia for neonatal hypoxic-ischaemic encephalopathy. Arch Dis Child Fetal Neonatal Ed. 2012;97:F398-404.

16. Barkovich AJ, Hajnal BL, Vigneron D, Sola A, Partridge JC, Allen F. Prediction of neuromotor outcome in perinatal asphyxia: evaluation of MR scoring systems. AJNR Am J Neuroradiol. 1998;19:143-149.

17. Weeke LC, Groenendaal F, Mudigonda K, et al. A novel magnetic resonance imaging score predicts neurodevelopmental outcome after perinatal asphyxia and therapeutic hypothermia. J Pediatr. 2018;192: 33-40.

18. Haugk M, Testori C, Sterz F, Uranitsch M, Holzer M, Behringer W, Herkner H; Time to Target Temperature Study Group. Relationship between time to target temperature and outcome in patients treated with therapeutic hypothermia after cardiac arrest. Crit Care. 2011;15(2):R101.

19. Perman SM, Ellenberg JH, Grossestreuer AV, Gaieski DF, Leary M, Abella BS, Carr BG. Shorter time to target temperature is associated with poor neurologic outcome in post-arrest patients treated with targeted temperature management. Resuscitation. 2015 Mar;88:114-9.

20. Lyon RM, Richardson SE, Hay AW, Andrews PJ, Robertson CE, Clegg GR. Esophageal temperature after out-of-hospital cardiac arrest: an observational study. Resuscitation. 2010 Jul;81(7):867-71.

21. den Hartog AW, de Pont AC, Robillard LB, Binnekade JM, Schultz MJ, Horn J. Spontaneous hypothermia on intensive care unit admission is a predictor of unfavorable neurological outcome in patients after resuscitation: an observational cohort study. Crit Care. 2010;14(3):R121.

22. Lin S, Scales DC, Dorian P, Kiss A, Common MR, Brooks SC, Goodman SG, Salciccioli JD, Morrison LJ. Targeted temperature management processes and outcomes after out-of-hospital cardiac arrest: an observational cohort study. Crit Care Med. 2014 Dec;42(12):2565-74.

23. Hovdenes J, Røysland K, Nielsen N, Kjaergaard J, Wanscher M, Hassager C, Wetterslev J, Cronberg T, Erlinge D, Friberg H, Gasche Y, Horn J, Kuiper M, Pellis T, Stammet P, Wise MP, Åneman A, Bugge JF. A low body temperature on arrival at hospital following out-of-hospital-cardiac-arrest is associated with increased mortality in the TTM-study. Resuscitation. 2016 Oct;107:102-6.

24. Benz-Woerner J, Delodder F, Benz R, Cueni-Villoz N, Feihl F, Rossetti AO, Liaudet L, Oddo M. Body temperature regulation and outcome after cardiac arrest and therapeutic hypothermia. Resuscitation. 2012 Mar;83(3):338-42.

25. Wang HE, Callaway CW, Peitzman AB, Tisherman SA. Admission hypothermia and outcome after major trauma. Crit Care Med. 2005 Jun;33(6):1296-301. 
26. Hsieh TM, Kuo PJ, Hsu SY, Chien PC, Hsieh HY, Hsieh CH. Effect of Hypothermia in the Emergency Department on the Outcome of Trauma Patients: A Cross-Sectional Analysis. Int J Environ Res Public Health. 2018 Aug 17;15(8):1769.

27. Erkens R, Wernly B, Masyuk M, Muessig JM, Franz M, Schulze PC, Lichtenauer M, Kelm M, Jung C. Admission Body Temperature in Critically III Patients as an Independent Risk Predictor for Overall Outcome. Med Princ Pract. 2020;29(4):389-395.

28. Murnin MR, Sonder P, Janssens GN, Henry CL, Polderman KH, Rittenberger JC, Dezfulian C; Post Cardiac Arrest Service. Determinants of heat generation in patients treated with therapeutic hypothermia following cardiac arrest. J Am Heart Assoc. 2014 Apr 29;3(3):e000580.

29. Uber AJ, Perman SM, Cocchi MN, Patel PV, Ganley SE, Portmann JM, Donnino MW, Grossestreuer AV. Increased Heat Generation in Postcardiac Arrest Patients During Targeted Temperature Management Is Associated With Better Outcomes. Crit Care Med. 2018 Jul;46(7):1133-1138.

30. Mietzsch U, Radhakrishnan R, Boyle FA, Juul S, Wood TR. Active cooling emperature required to achieve therapeutic hypothermia correlates with short-term outcome in neonatal hypoxic-ischaemic encephalopathy. J Physiol. 2020;598(2):415-424.

31. Bandoła D, Rojczyk M, Ostrowski Z et al. Expermental setup and measurements of the heat transfer rate during newborn brain cooling process. Arch Thermodyn. 2018;39(3):85-96.

32. Walas, W., Bandoła, D., Ostrowski, Z. et al.Theoretical basis for the use of non-invasive thermal measurements to assess the brain injury in newborns undergoing therapeutic hypothermia. Sci Rep 10, 22167 (2020). https:// doi.org/10.1038/s41598-020-79009-3.

33. Shah P, Beyene J, To T, Ohlsson A, Perlman M. Postasphyxial hypoxic-ischemic encephalopathy in neonates: outcome prediction rule within 4 hours of birth. Arch Pediatr Adolesc Med. 2006;160:72936.

34. Ambalavanan N, Carlo WA, Shankaran S, et al. Predicting outcomes of neonates diagnosed with hypoxemic-ischemic encephalopathy. Pediatrics. 2006;118:2084-93.

35. Wayock CP, Meserole RL, Saria S, Jennings JM, Huisman TA, Northington FJ, Graham EM. Perinatal risk factors for severe injury in neonates treated with whole-body hypothermia for encephalopathy. Am J Obstet Gynecol. 2014 Jul;211(1):41.e1-8.

36. Malin GL, Morris RK, Khan KS. Strength of association between umbilical cord pH and perinatal and long term outcomes: systematic review and meta-analysis. BMJ. 2010;340:c1471.

37. Laptook AR, Shankaran S, Ambalavanan N, Carlo WA, McDonald SA, Higgins RD, Das A; Hypothermia Subcommittee of the NICHD Neonatal Research Network. Outcome of term infants using apgar scores at 10 minutes following hypoxic-ischemic encephalopathy. Pediatrics. 2009 Dec;124(6):161926.

38. Shah P, Anvekar A, McMichael J, Rao S. Outcomes of infants with Apgar score of zero at 10 min: the West Australian experience. Arch Dis Child Fetal Neonatal Ed. 2015 Nov;100(6):F492-4.

39. Muniraman H, Gardner D, Skinner J, Paweletz A, Vayalakkad A, Chee YH, Clifford C, Sanka S, Venkatesh V, Curley A, Victor S, Turner MA, Clarke P. Biomarkers of hepatic injury and function in 
neonatal hypoxic ischemic encephalopathy and with therapeutic hypothermia. Eur J Pediatr. 2017 Oct;176(10):1295-1303, Erratum in: Eur J Pediatr. 2017 Oct;176(10 ):1305-1306.

40. Agrawal J, Shah GS, Poudel P, Baral N, Agrawal A, Mishra OP. Electrocardiographic and enzymatic correlations with outcome in neonates with hypoxic-ischemic encephalopathy. Ital J Pediatr. 2012 Jul 23;38:33.

41. Türker G, Babaoğlu K, Gökalp AS, Sarper N, Zengin E, Arisoy AE. Cord blood cardiac troponin I as an early predictor of short-term outcome in perinatal hypoxia. Biol Neonate. 2004;86(2):131-7.

42. Montaldo P, Rosso R, Chello G, Giliberti P. Cardiac troponin I concentrations as a marker of neurodevelopmental outcome at 18 months in newborns with perinatal asphyxia. J Perinatol. 2014 Apr;34(4):292-5.

43. Shastri AT, Samarasekara S, Muniraman H, Clarke P. Cardiac troponin I concentrations in neonates with hypoxic-ischaemic encephalopathy. Acta Paediatr. 2012 Jan;101(1):26-9,

44. Trevisanuto D, Picco G, Golin R, Doglioni N, Altinier S, Zaninotto M, Zanardo V. Cardiac troponin I in asphyxiated neonates. Biol Neonate. 2006;89(3):190-3.

45. Zhou WJ, Yu F, Shi J, Yang H, Zou SJ, Jiang YM. Serum Levels of Cardiac Troponin I in Asphyxiated Neonates Predict Mortality. Clin Lab. 2016 Aug 1;62(8):1427-1434.

\section{Figures}




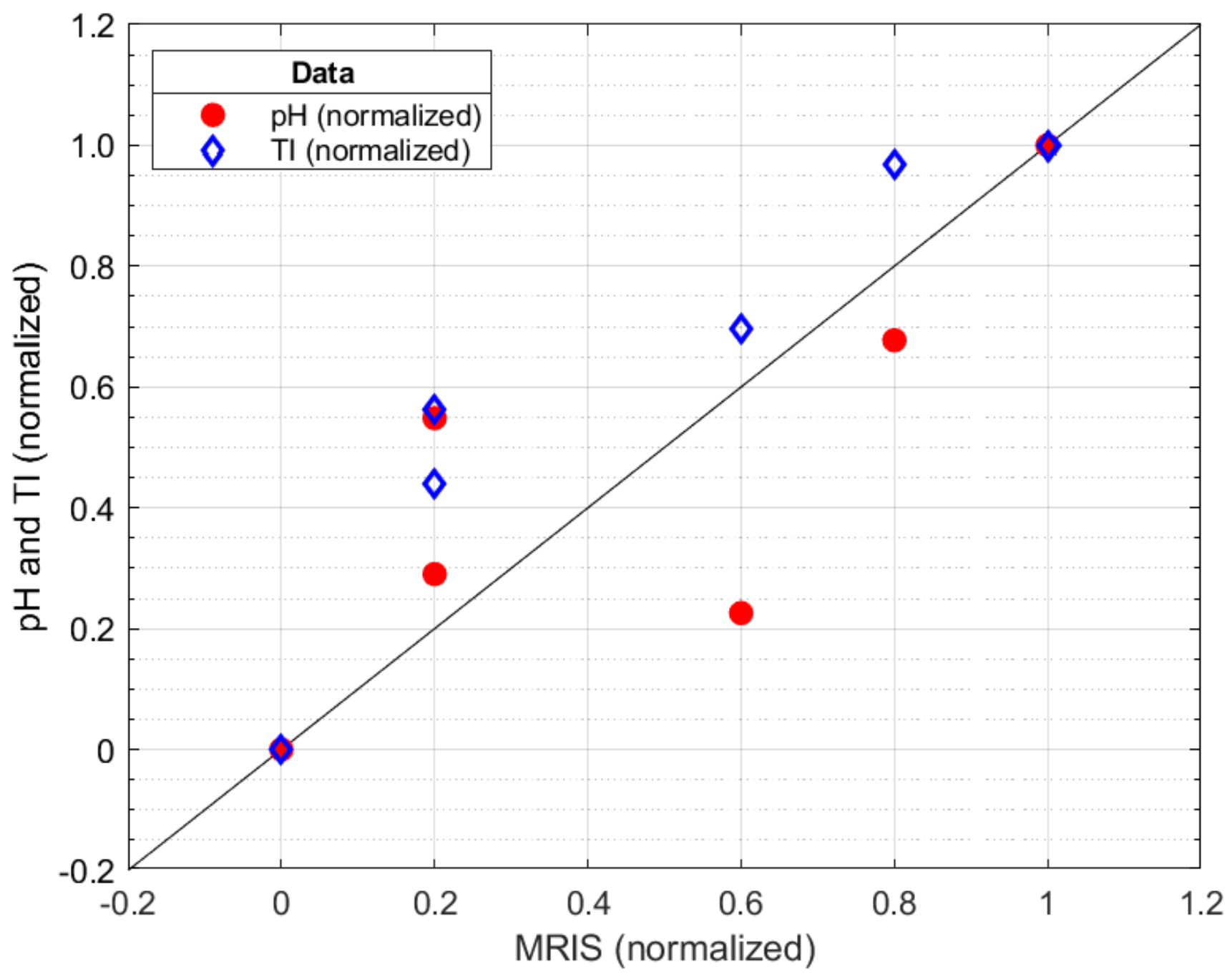

Figure 1

Correlation between the MRIS and the $\mathrm{pH}$ and TI scales (all variables were min-max normalized to [0;1]) 